\title{
The Effect of Contact-Based Interventions on the Attitudes and Behaviors of Nursing Students towards People with Mental Illness: A Literature Review
}

\author{
Mohammad Abdel Qader M. Al-Ma'ani' ${ }^{1}$ Ayman M. Hamdan-Mansour ${ }^{1,2}$ \\ ${ }^{1}$ School of Nursing, University of Jordan, Amman, Jordan \\ ${ }^{2}$ Faculty of Nursing, Al-Ahliyya Amman University, Amman, Jordan \\ Email: mohammadalmaani@yahoo.com
}

How to cite this paper: Al-Ma'ani, M.A.Q.M. and Hamdan-Mansour, A.M. (2020) The Effect of Contact-Based Interventions on the Attitudes and Behaviors of Nursing Students towards People with Mental Illness: A Literature Review. Open Journal of Nursing, 10, 260-276.

https://doi.org/10.4236/ojn.2020.103018

Received: February 12, 2020

Accepted: March 21, 2020

Published: March 24, 2020

Copyright $\odot 2020$ by author(s) and Scientific Research Publishing Inc. This work is licensed under the Creative Commons Attribution International License (CC BY 4.0).

http://creativecommons.org/licenses/by/4.0/

\begin{abstract}
Background: Student nurses and other healthcare students are the future mental health professionals and have the potential for changing the future of mental healthcare. Therefore, their negative attitudes and behaviors should be screened and corrected by effective anti-stigma interventions. Otherwise, they would likely withhold some health services and practice coercive treatments once planning care to people with mental illness. However, little is known on effective approaches to correct these negative attitudes and behaviors, despite the previous reviews that have shown that contact-based interventions have demonstrated positive attitudinal and behavioral changes for nursing students towards people with mental illness. Aim: The aim of this literature review was to compile the available research evidence on contact-based interventions that have targeted the attitudes and behaviors of nursing students towards people with mental illness. Methods: The relevant literature was extracted by searching electronic databases (MEDLINE, PsycINFO, and CINAHL) and by hand checking reference lists of past similar reviews. Results: Eleven studies were retrieved and included in this review. The included studies in this review either have employed social contact interventions, video-based social contact interventions, or both types for the aim of combining or comparing. Furthermore, the included studies either have targeted the attitudes of nursing students towards people with mental illness (including prejudice), or a combination of attitudinal and behavioral outcomes (including behavioral intentions and social distance). No studies have targeted behavioral outcomes solely. Conclusions: From the available literature, the current authors cannot draw conclusions on the most effective type, form, or in-
\end{abstract}


gredients of contact-based interventions among nursing students, as previous literature has large variations. No consistency was found in the previous studies regarding the types or contents of effective contact-based interventions. The compiled evidence in this review, has suggested that contact-based interventions (both social contact and video-based social contact) have been effective in changing the attitudes and behaviors of nursing students favorably, similarly to what previous reviews have found.

\section{Keywords}

Contact-Based Interventions, Attitudes, Behaviors, Nursing Students, Mental Illness

\section{Introduction}

Worldwide, people with mental illness suffer from the stigma associated with their illness [1] [2] [3]. The stigma of mental illness is best defined as a construct of interrelated components of poor knowledge (stereotypes), negative attitudes (prejudice), and negative behaviors (discrimination) [4] [5] [6]. Stigmatizing attitudes and behaviors endorsed by the public towards people with mental illness are broad [7] [8] [9] and extend to all populations including university students [10].

University students from different schools and disciplines such as health (medicine [11], nursing [12], dentistry [13] [14], and pharmacy [15]), humanities [16] [17], engineering [16], and business [18] frequently hold negative stigmatizing attitudes and behaviors towards people with mental illness. Nursing students, when having been compared to other university students, have reported more positive attitudes and behaviors towards people with mental illness [19] [20]. Yet, when they have been compared to the general public, they have shown more negative attitudes and behaviors towards those people [21] [22], such as the beliefs of dangerousness and unpredictability as well as the desire to social distance [20].

It is important to carefully assess the attitudes and behaviors of nursing students towards people with mental illness and to correct negative ones before their first contact in psychiatric training to ensure that students have more positive experiences [23]. Furthermore, student nurses and other healthcare students are the future mental health professionals and have the potential for changing the future of mental healthcare. Therefore, their negative attitudes and behaviors should be screened and corrected by effective anti-stigma interventions. Otherwise, they would likely withhold some health services and practice coercive treatments once planning care to people with mental illness [24]. This would, in turn, limit the access of those people to mental healthcare services [25]. Their negative attitudes and behaviors could further negatively impact therapeutic nurse-patient relationships, and eventually might lead to negative ramifications 
of these negative attitudes and behaviors on those patients [22].

However, little is known on effective approaches to correct these negative attitudes and behaviors [10] [23], despite the previous reviews [10] [23] [26]-[36] that have shown that contact-based interventions have demonstrated positive attitudinal and behavioral changes for nursing students towards people with mental illness. The following is a brief description of the aim and focus of these previous reviews. Corrigan and colleagues [26] meta-analyzed the previous literature that have assessed the effect of anti-stigma strategies (including protest, education, and contact) on public stigma of mental illness among young adults and adolescents. Couture and Penn [27] reviewed the previous literature on the relationship between contact and stigma reduction. They reviewed both retrospective and prospective contact studies. Griffiths and colleagues [28] performed a meta-analysis of previous randomized controlled trials that have examined the effect of different anti-stigma programs on personal and perceived stigma, self-stigma, and social distance. Gronholm and colleagues [29] conducted a narrative synthesis of previous literature that has discussed interventions to reduce discrimination and stigma among the general public and key target groups (including healthcare professionals, police officers, and students). Heim and colleagues' [23] systematic review collected the previously available evidence on anti-stigma interventions among medical and nursing students in Low- and Middle-Income Countries (LMICs). Kolodziej and Johnson [30] conducted a meta-analytic review on the effect of interpersonal contact between mental healthcare professionals or students and people with mental illness on the attitudes and behaviors of the former group towards the latter group. Mehta and colleagues [31] synthesized the previous global literature on interventions shown effectiveness on reducing the stigma of mental illness and discrimination in the medium and long terms. They also synthesized similar literature but in LMICs only. Morgan and colleagues [32] reviewed and evaluated the previous evidence in regard to effective interventions on public stigma towards people with severe mental illness only (schizophrenia, psychosis, and bipolar disorders only). Pinto-Foltz and Logsdon [33] summarized the previously available evidence of mental illness stigma-reducing interventions in the disciplines of nursing, psychology, and psychiatry. Stubbs [34] examined the effect of anti-stigma interventions among healthcare students and professionals in the previous literature. Thornicroft and colleagues [35], in their narrative review, summarized the previous global literature (both in high-income and LMICs) that has focused on effective interventions for the general public, school and college students, healthcare professionals, and other populations; that have targeted their stigma towards and discrimination against people with mental illness. Yamaguchi and colleagues [36] narratively reviewed the previous literature that has examined the effect of anti-stigma interventions (educational and contact interventions) on reducing the stigma of mental illness and improving the awareness of mental health problems among young people. Yamaguchi and colleagues [10], in 
another a review, systematically reviewed previous intervention studies that have employed short-time anti-stigma interventions in order to reduce the stigma of mental illness among university and college students.

In Jordan, only two studies [37] [38] have assessed the attitudes of Jordanian nursing students towards people with mental illness. Abuhammad and colleagues [37] found that Jordanian nursing students had negative attitudes towards people with mental illness while Hamaideh and Mudallal [38] found that Jordanian nursing students had positive attitudes towards people with mental illness. No study has employed a contact-based intervention of any type among a sample of nursing students was conducted in Jordan.

The current review attempted to provide what is somewhat different than the previous ones, with the aim to compile the available research evidence on contact-based interventions that have targeted the attitudes and behaviors of nursing students towards people with mental illness. No prior review is identical to our review in terms of the intervention of interest (only contact-based interventions of both types), the population of interest (only nursing students), and the outcomes of interest (only attitudes and behaviors towards people with mental illness).

\section{Methods}

There is a vast literature on the topic of this review, wherefore; a search strategy was used to include only pieces of literature that have focused on the population, the intervention, and the outcomes of interest. Also, clear search strategy is crucial for ensuring the rigor of literature reviews, because ill-defined search strategy might yield inaccurate and incomplete results [39].

The relevant literature was extracted by searching electronic databases and by hand checking reference lists of past similar reviews [10] [23] [26]-[36]. Two different strategies were used to retrieve the maximum number of relevant materials [40]. These search strategies were adapted from a previous similar review [10]. The following electronic databases were exhaustively searched to extract the relevant literature: MEDLINE, PsycINFO, and the Cumulative Index to Nursing and Allied Health Literature (CINAHL). These databases were particularly searched because they were the most frequent searched databases in previous similar reviews [10] [23] [30] [31] [32] [33] [35] [36]. No time limit was set in order to retrieve the maximum number of relevant materials.

Initially, the search was conducted using the following keywords separately: 1) keywords that relate to attitudes (which include attitude and prejudice), 2) Keywords that relate to behaviors (which include behavior, behavioral intentions, discrimination, and social distance), 3) Keywords that relate to mental illness, e.g., mental illness or its synonymous, psychiatric disorder or its synonymous, 4) Keywords that relate to contact-based intervention including contact, contact intervention, contact-based intervention, and anti-stigma contact intervention, 5) Keywords that relate to nursing students including nursing students and stu- 
dent nurses. Then, the Boolean operators (AND, OR) were used between these keywords to retrieve relevant materials only.

The inclusion criteria for considering relevant materials in this review were: 1 ) published in English language only, 2) articles employed contact-based interventions in both forms (live or video-based) alone or in combination with other anti-stigma interventions such as educational interventions, 3) targeted nursing students only as participants or targeted also other students for the aim of comparison with nursing students, and 4) targeted at least one of the attitudinal outcomes (including prejudice) or the behavioral outcomes (including behavioral intentions, discrimination, or social distance) or both outcomes. On the other hand, incomplete reports, editorial papers, conference proceedings, opinion papers, abstracts, posters, unpublished materials, and grey literature were excluded from this review. Further exclusion of materials discussed the effect of student-patient contact in nursing curricula's psychiatric clinical trainings, rotations, placements, clerkships, secondments, or affiliations were done, as excluded by previous similar review [34].

At first, searching for each of the abovementioned keywords was performed separately for each one by using the selected electronic databases. This search yielded the following results: attitudes $(582,290$ records), behaviors $(1,514,394$ records), mental illness (276,998 records), contact-based intervention $(342,896$ records), and nursing students (58,282 records). Then, as shown in Figure 1, searching for the combination of these keywords using the same electronic databases came back with 21 articles. Then, removing duplicates resulted in 8 articles only. After that, screening of the titles of those articles resulted in exclusion of 6 articles, as the titles were not relevant to this review; 2 articles left [41] [42]. Furthermore, checking the reference lists of past similar reviews [10] [23] [26]-[36] yielded 21 articles. Eight of these articles were excluded due to employing nursing curricula's psychiatric clinical trainings, rotations, placements, clerkships, secondments, or affiliations, one study [43] was excluded due to targeting medical students, two studies [44] [45] were excluded due to employing educational intervention, and one study [46] was excluded due to targeting outcomes other than attitudes and behaviors; 9 articles left. Therefore, the sum of resulted articles from those two different searching strategies became 11 articles.

\section{Results}

Eleven studies [41] [42] [47]-[55] were reviewed carefully and included in this review. In Table 1, each included study in this review was summarized and described in terms of: authors, year of publication, aim, intervention, and main results. These descriptions were particularly reported because they were the most frequent reported in similar tables included in previous similar reviews [10] [23] [28] [31] [32] [33] [36].

Yamaguchi and colleagues [10] reviewed the interventions that have been developed to improve the attitudes and behaviors of university students (including 


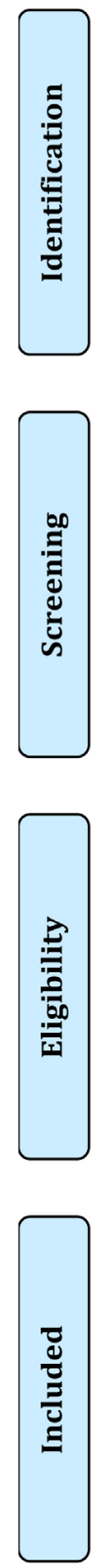
Records identified through electronic databases searching $(\mathrm{n}=21)$

\section{Additional records identified through} checking reference lists of past similar reviews

$$
(\mathrm{n}=21)
$$
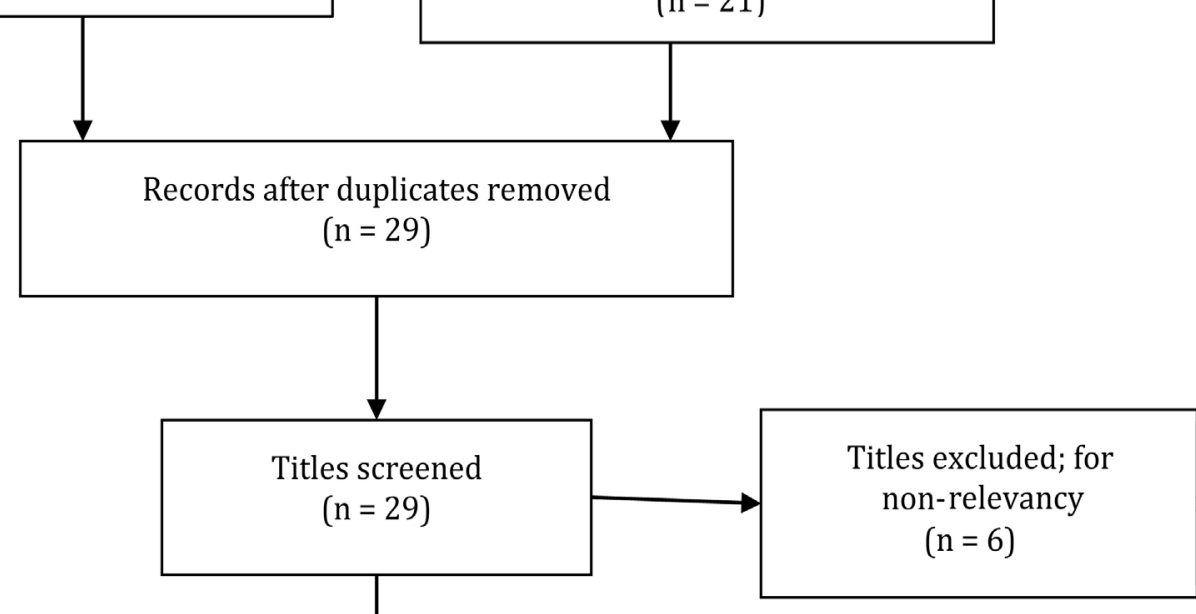

Figure 1. Search strategy and outcomes.

nursing students) towards people with mental illness and classified these interventions into eight categories; two of these categories were contact-based interventions (social contact and video-based social contact). Social contact is any face-to-face interaction between people with mental illness and university students; in which people sharing their lived experiences of having such illness. Video-based social contact is any media that shows people with mental illness talking about their own illness' experiences. Both types have shown effectiveness in improving the attitudes and behaviors of university students generally and nursing students particularly towards people with mental illness. 
Table 1. Summary of studies included in this review.

\begin{tabular}{|c|c|c|c|}
\hline $\begin{array}{c}\text { Reference; Type of } \\
\text { Contact-Based } \\
\text { Interventions }\end{array}$ & Aim & Intervention & Main Results \\
\hline
\end{tabular}

Brown (2009) [47];

video-based social contact.

Clement, van

Nieuwenhuizen,

Kassam, Flach,

Lazarus, De Castro,

McCrone, Norman,

and Thornicroft

(2012) [48]; both

social contact and

video-based social

contact.
To assess the effect of a faith-based service learning project on reducing the stigma of mental illness and substance abuse as well as on increasing student nurses' knowledge and skills on community mental health.

To compare the impact of a DVD-based contact, a live contact, and a lecture control on decreasing the stigma of mental illness.

To assess the impact of age and video-based educational

Coleman (2007) [49]; video-based social contact.
The faith-based intervention was a 90-minutes workshop included the following:

1) A PowerPoint presentation on information about causes, signs, symptoms, and treatments of mental illness and substance abuse. 2) A brief video provided commentaries from individuals with mental illness, their families, and faith communities that give support.

3) Interactive learning activity or game.

Nursing students, who were randomly assigned to the DVD-based contact group, watched a DVD of people with mental illness and their informal care providers telling their first-hand experiences about mental illness and associated stigma. The DVD lasted for 71 minutes and followed by discussion. On the other hand, student nurses who were assigned to the live intervention group attended a presentation primarily delivered by a person with mental illness and informal care provider in which they provided personal testimonies about their experiences of mental illness and its stigma. The presentation followed by factual information delivered by one of the researchers regarding to the key points discussed by the presenters. Finally, questions-answers session was took place in which the presenters answered student nurses' concerns.

Nursing students in the experimental group watched a 60 -minutes educational videotape on schizophrenia. This videotape gave information about the causes and treatments of schizophrenia, as well as consequences for individuals living with schizophrenia. It included interviews with persons with schizophrenia and their families who provided their experiences of having this mental illness.
Decrease in the stigma of mental illness among nursing students and increasing student nurses' knowledge and skills about community mental health.

Both live and DVD-based contact groups had more positive attitudes and behaviors than the control group (lecture).

Neither age nor video-based education about schizophrenia had a positive impact on the attitudes of nursing students towards people with schizophrenia. 


\begin{tabular}{|c|c|c|c|}
\hline $\begin{array}{l}\text { Happell, Byrne, } \\
\text { Platania-Phung, } \\
\text { Harris, Bradshaw, and } \\
\text { Davies (2014) [50]; } \\
\text { social contact. }\end{array}$ & $\begin{array}{l}\text { To measure the impact of a } \\
\text { course delivered by an } \\
\text { individual with mental illness } \\
\text { on nursing students' attitudes } \\
\text { towards people with mental } \\
\text { illness as well as their } \\
\text { intentions to a pursue a career } \\
\text { in psychiatric mental health } \\
\text { nursing in the future. }\end{array}$ & $\begin{array}{l}\text { The course delivered by a person with } \\
\text { mental illness continued for } 12 \text { weeks } \\
\text { with a primary focus on recovery. The } \\
\text { contents included understanding of the } \\
\text { recovery in mental health context, the } \\
\text { role of nurses in the recovery process, } \\
\text { and the importance of collaboration } \\
\text { with patients with mental illness to } \\
\text { promote recovery. }\end{array}$ & $\begin{array}{l}\text { Nursing students who attended the } \\
\text { course delivered by the individual with } \\
\text { mental illness showed positive changes } \\
\text { in their intentions to pursue a future } \\
\text { career in psychiatric mental health } \\
\text { nursing and a decrease in their negative } \\
\text { stereotypes towards people with mental } \\
\text { illness. }\end{array}$ \\
\hline $\begin{array}{l}\text { Imperio }(2016)[41] ; \\
\text { video-based social } \\
\text { contact. }\end{array}$ & $\begin{array}{l}\text { To assess the effect of a } \\
\text { filmed-contact intervention } \\
\text { delivered to student nurses on } \\
\text { minimizing their stigmatizing } \\
\text { attitudes towards people with } \\
\text { mental illness. }\end{array}$ & $\begin{array}{l}\text { The filmed-contact intervention video } \\
\text { was a TED Talks video in which a } \\
\text { woman talked about successfully } \\
\text { managing her schizophrenia; currently } \\
\text { holding a doctorate degree in law and } \\
\text { teaching in a reputable university. }\end{array}$ & $\begin{array}{l}\text { Reduction in stigmatizing attitudes of } \\
\text { nursing students towards people with } \\
\text { mental illness. }\end{array}$ \\
\hline $\begin{array}{l}\text { İnan, Günüşen, } \\
\text { Duman, and Ertem } \\
\text { (2018) [51]; both } \\
\text { social contact and } \\
\text { video-based social } \\
\text { contact. }\end{array}$ & $\begin{array}{l}\text { To assess the effect of module } \\
\text { on psychiatric mental health } \\
\text { nursing, clinical practice, and } \\
\text { anti-stigma program on the } \\
\text { attitudes of student nurses } \\
\text { towards mental illness. }\end{array}$ & $\begin{array}{l}\text { The anti-stigma program lasted for } 8 \\
\text { sessions over } 4 \text { days; with each session } \\
\text { lasted from } 120 \text { to } 180 \text { minutes. The } \\
\text { program included the following: } \\
\text { interactive information, group } \\
\text { discussions, video presentations, } \\
\text { watching documentary films } \\
\text { portraying the lives of patients with } \\
\text { schizophrenia, reviewing articles, } \\
\text { activities, visiting patients with } \\
\text { schizophrenia and their families in } \\
\text { their own communities and } \\
\text { interacting with them. }\end{array}$ & $\begin{array}{l}\text { Positive changes in student nurses' } \\
\text { dangerousness attitudes and their } \\
\text { social distance from people with } \\
\text { mental illness. }\end{array}$ \\
\hline $\begin{array}{l}\text { Itzhaki, Meridan, } \\
\text { Sagiv-Schifter, and } \\
\text { Barnoy (2016) [52]; } \\
\text { both social contact } \\
\text { and video-based } \\
\text { social contact. }\end{array}$ & $\begin{array}{l}\text { To assess changes in attitudes } \\
\text { and intentions to work with } \\
\text { patients with mental illness } \\
\text { among student nurses after an } \\
\text { intervention of mental health. }\end{array}$ & $\begin{array}{l}\text { The intervention was delivered during } \\
\text { a mental health nursing course. It } \\
\text { lasted for } 70 \text { hours and involved five } \\
\text { parts: } \\
\text { 1) A face-to-face meeting with two } \\
\text { persons with mental illness (one } \\
\text { had schizophrenia and the other had } \\
\text { mood disorder) who shared } \\
\text { their lived } \\
\text { experiences about mental illness. } \\
\text { 2) A meeting with a woman who } \\
\text { suffered from anorexia nervosa } \\
\text { in her teens. } \\
\text { 3) A } 50 \text {-minutes film on a doctoral } \\
\text { degree holder in psychology, who } \\
\text { told her story of living with mental } \\
\text { illness since her adolescence, } \\
\text { followed by discussions. } \\
\text { 4) Two simulations by an actress } \\
\text { who played a persona of a manic or a } \\
\text { depressive patient in acute phase. } \\
\text { 5) Lectures about mental illness } \\
\text { and treatments delivered by } \\
\text { mental health nurses. }\end{array}$ & $\begin{array}{l}\text { The intervention resulted in improving } \\
\text { of student nurses' attitudes towards } \\
\text { patients with mental illness but did not } \\
\text { result in improving their intentions to } \\
\text { work with those patients. }\end{array}$ \\
\hline
\end{tabular}




\section{Continued}

Martínez-Martínez,

Sánchez-Martínez,

Sales-Orts, Dinca,

Richart-Martínez,

and Ramos-Pichardo

(2019) [53]; social

contact.

Sadow and Ryder

(2008) [54]; social

contact.

Vaghee, Lotfabadi,

Salarhaji, Vaghei, and

Hashemi (2018) [55];

social contact.

Winkler, Janoušková Kožený, Pasz, Mladá, Weissová, Tušková and Evans-Lacko (2017) [42]; both social contact and video-based social contact.
To assess the effect of a direct contact with people with mental illness on the stigma of nursing students towards those people.

To investigate the impact of nursing students' exposure to personal messages delivered by an individual with mental illness in recovery on decreasing stigmatizing attitudes of nursing students towards people with mental illness.

To compare the impact of a contact-based education with the impact of a commitment and acceptance-based training on empathy of student nurses towards people with mental illness.

To investigate the effect of short videos on reducing stigmatizing attitudes and behaviors of student nurses' towards people with mental illness as well as compared the effect of short videos with other methods (seminar and informational leaflet).
A 90-minutes session in which a mental health care provider, an individual with mental illness, and a family member telling their experiences about the mental illness. Then, a 30-minute questions and answers' session was held.

Nursing students in the intervention group attended 3 presentations delivered by different individuals with mental illness in the recovery phase.

In the contact-based education; 3 patients with stable mental illness (one had schizophrenia, one had bipolar type 1 , and one had major depression) talked about their illness' experiences. Each patient talked for one-hour session.

One of the experimental groups attended a 45-minute seminar was developed by the cooperation of the authors, persons with mental illness, and mental health professionals. The seminar was presented by both a mental health professional and a person with mental illness as well. On the other hand, the other experimental group watched 3 short videos (each of them were 2 - 3 minutes).
A decrease in fear, perceived danger, avoidance, segregation, and coercive attitudes were noticed after the intervention as well as increase in positive feelings (help and compassion) among nursing students.

Decreasing in stigmatizing attitudes of student nurses towards people with mental illness.

Both the contact-based education and the acceptance and commitment-based therapy were successful in increasing the level of empathy towards mental illness among student nurses. No significant differences were found between these two methods.

Seminar had the strongest and the most stable positive impact on student nurses' attitudes and behaviors towards people with mental illness. Also, short videos were effective and stable over time.

The included studies in this review either have employed social contact interventions [50] [53] [54] [55], video-based social contact interventions [41] [47] [49], or both types for the aim of combining [51] [52] or comparing [42] [48]. Furthermore, the included studies either have targeted the attitudes of nursing students towards people with mental illness (including prejudice) [49] [50] [54] [55], or a combination of attitudinal and behavioral outcomes (including behavioral intentions and social distance) [41] [42] [47] [48] [51] [52] [53]. No studies have targeted behavioral outcomes solely.

\subsection{Studies that Have Employed Social Contact Interventions}

Four studies have employed social contact interventions among nursing students for the aim of improving their attitudes and behaviors towards people with mental illness [50] [53] [54] [55]. Martínez-Martínez and colleagues [53] devel- 
oped and assessed the impact of a direct contact's intervention with people with mental illness with the aim to improve the attitudes of student nurses. The intervention was a single 90 -minutes session involved a mental health professional, an individual with mental illness, and a family member of another person with mental illness who spoke about their first-hand experiences of having mental illness and recovery after that, and then, they received and answered questions posed by nursing students. After the intervention, a decrease in fear, perceived danger, avoidance, segregation, and coercive attitudes were found among nursing students towards those people, as well as increase in positive feelings (tendency to help and compassion).

Sadow and Ryder [54] recruited two groups of nursing students to assess the effect of personal messages by a recovered person with mental illness on reducing the student nurses' stigmatizing attitudes towards people with mental illness. The first group (27 nursing students) received three trainings by a psychologist focused on the psychosocial rehabilitation principles. Then, they asked questions got answered by the psychologist. The second group (30 nursing students) also received the same trainings, in addition to a presentation by an individual with mental illness in recovery who discussed lived experiences of mental illness and answered nursing students' questions. The results indicated that the second group, who attended the presentation, changed attitudes towards people with mental illness and mental health professionals positively. No such change was found among the first group (who did not attend the presentation).

Happell and colleagues [50] aimed to determine the effect of a 12-weeks mental health course delivered by an individual with mental illness and focused on recovery, on nursing students' attitudes towards people with mental illness and intentions to pursue a career in mental health nursing. They further compared its effect with the effect of a 12-weeks length traditional mental health course delivered by a nurse. The results showed that nursing students, who attended the course delivered by a person with mental illness, reported a reduction in negative attitudes towards people with mental illness and a positive change in their intentions to become mental health nurses in the future, that were not reported by nursing students who attended the traditional mental health course.

Vaghee and colleagues [55] selected 111 nursing students using different samples techniques in Iran and distributed them to 3 groups: contact-based education, acceptance and commitment-based training, and control group. Nursing students who were in group of contact-based education met 3 patients with mental illness (one with schizophrenia, one with bipolar disorder - type 1, and one with major depression) who talked about their experiences of mental illness. Nursing students in the acceptance and commitment-based training' group, had a workshop held by holders of a masters degree in clinical psychology and psychiatric nursing. The control group received regular psychiatric nursing clerkship. The results showed that both groups of contact-based education and acceptance and commitment-based training, had an improvement in their empa- 
thy towards people with mental illness. On the other hand, the control group had no such improvement. Further, no significant difference was noticed between the group of contact-based education and the group of acceptance and commitment-based training; in terms of empathy towards people with mental illness.

\subsection{Studies that Have Employed Video-Based Social Contact Interventions}

Three studies shave employed video-based social contact interventions to improve the attitudes and behaviors of student nurses towards people with mental illness [41] [47] [49]. Imperio [41] investigated the impact of a filmed-contact intervention on stigmatizing attitudes of 37 pre-licensure nursing students towards people with mental illness. The film was one of the TED Talks videos which featured a woman shared her experiences of adaptation with schizophrenia (challenges and successes) that led her to obtain a doctorate degree in law and teach in prestigious university. Nursing students, who watched the film, demonstrated reduction in their stigmatizing attitudes towards people with mental illness.

Brown [47] evaluated the impact of a faith-based program on the stigma of mental illness and substance abuse as well as the knowledge and skills on community mental health among a sample of nursing students. The faith-based program was a hour and half workshop that involved the following components: 1) a PowerPoint presentation about causes, signs, symptoms, and treatments of mental illness and substance abuse, 2) a brief video presented commentaries from persons with mental illness, their families, and faith communities that support those people, and 3) interactive learning activity or game. After the program, a reduction in mental illness stigma as well as improvement in the knowledge and skills about community mental health, were noticed among nursing students. In contrary, Coleman [49] determined the effect of video-based educational materials focused on schizophrenia, on the attitudes of 240 student nurses towards people with mental illness. Nursing students who were randomly assigned to the intervention group, viewed a one-hour educational videotape discussed schizophrenia. This video gave information on the causes and treatments of schizophrenia. It further contained interviews with persons with schizophrenia and their families who shared the consequences of illness on their family dynamics, personal relationships, and overall functioning. On the other hand, nursing students, in the control group, watched a videotape about diabetes, in which a discussion of the causes and treatments of diabetes was presented. The results suggested no effect for the schizophrenia's videotape on the attitudes of nursing students towards people with schizophrenia.

\subsection{Studies that Have Employed Both Social Contact and Video-Based Social Contact Interventions}

Four studies have employed both types of contact-based intervention (social 
contact and video-based social contact) for improving the attitudes and behaviors of nursing students towards people with mental illness [42] [48] [51] [52]. Two studies have employed the both types in order to combine them in one intervention [51] [52]. Inan and colleagues [51] assessed the impact of a psychiatric nursing module, a clinical practice, and an anti-stigma program on a sample of 64 nursing students' attitudes and behaviors towards mental illness in Turkey. Only the anti-stigma program included contact ingredients. In further details, it included the following parts: 1) information on myths on mental illness, 2) short videos by mental health professionals, 3) documentary films which described the lives of patients with schizophrenia, 4) mental illness stigma articles, 5) visiting one of the associations that concerns about patients with schizophrenia and their families, and 6) visiting persons with mental illness and their families. It continued 8 sessions ( 2 - 3 hours for each session). After the mental health nursing module, the clinical practice, and the anti-stigma program, a decline in the dangerousness' perceptions and the desire for social distance were noticed. Itzhaki and colleagues [52] employed a planned intervention of a mental health course among a convenience sample of 101 third year undergraduate nursing students and assessed its effect on changes in attitudes and intentions to work with patients with mental illness (treat, specialize, or work in mental health field). The intervention (70 hours) was consisted of the following components: 1) A face-to-face meeting with two persons with mental illness (schizophrenia and mood disorder) who shared their experiences of mental illness, 2) a meeting with a woman with a diagnosis of anorexia nervosa from her teens, 3) a film featured the story of well-coping women with mental illness who eventually got a doctoral degree in psychology, 4) two simulations by an actress who played the character of a manic or a depressive patient at psychotic phase, and 5) lectures about mental illness and treatments by a psychiatric nurse. The intervention improved the student nurses' attitudes towards patients with mental illness. Yet, it did not improve their intentions of working with them.

On the other hand, two studies have employed the both types to make a comparison between them in term of effectiveness [42] [48]. Winkler and colleagues [42] investigated the effect of short videos on reducing the mental illness stigma (attitudes and behaviors) among student nurses, as compared with an informational leaflet and a seminar involved a direct contact with a person with a mental illness. Both the short videos and the seminar included contact components. The short videos were of a 2 - 3 minutes long that featured people with mental illness talking about their mental illness. The seminar ( 45 minutes) was delivered by a mental health professional and a person with mental illness. The results concluded that the seminar was the best intervention in terms of effectiveness and stability over time. However, the effect of short videos was considerable and stable as well. Clement and colleagues [48] assessed the effect of three different anti-stigma interventions and made a comparison between them in term of effectiveness for improving the attitudes and behaviors of 216 nursing students. The first intervention was a DVD that sowed people with mental illness and their in- 
formal caregivers talking about their mental illness' experiences, followed by a discussion. The second intervention was a live intervention that involved personal stories of a person with mental illness and informal caregiver about their experiences of mental illness and stigma, as well as information provided by the researcher commenting on their stories. The third intervention was a lecture by a mental health nurse on mental illness stigma. The results indicated that both the DVD and the live interventions were more effective than the lecture intervention in improving the attitudes and behaviors of nursing students towards people with mental illness. The results further revealed no differences in effectiveness between the DVD and the live interventions.

\section{Conclusions}

In this paper, a review of the literature on contact-based interventions among nursing students that have targeted their attitudes and behaviors towards people with mental illness was undertaken. From the available literature, the current authors cannot draw conclusions on the most effective type, form, or ingredients of contact-based interventions among nursing students, as previous literature has large variations. No consistency was found in the previous studies in regards to the types or contents of effective contact-based interventions. Moreover, we believe that there is no way to meta-analyze the previous literature due to the lack of studies and the differences of these studies in terms of outcomes, data collection methods, and contents of contact-based interventions. However, the compiled evidence in this review, has suggested that contact-based interventions (both social contact and video-based social contact) have been effective in changing the attitudes and behaviors of nursing students favorably, similarly to what previous reviews have found [10] [23] [29].

Further research is needed to confirm the findings of this review. Future research is also needed to find out the most effective form and contents of contact-based interventions for nursing students. Also, more studies are needed to understand the process by which contact-based interventions (both types) affect positively the attitudes and behaviors of nursing students towards people with mental illness. Further, time-series and longitudinal studies are needed to measure the effect of contact-based interventions of both types over time, because only a few studies measured long-term effects. Moreover, as no previous study has targeted behavioral outcomes solely in terms of behavioral intentions, social distance, and discrimination, future research should be directed to this area, since the ultimate goal of contact-based interventions and other anti-stigma interventions is to change actual behaviors towards people with mental illness [56]. Finally, as no studies have been found in the Arab world in general and Jordan in particular, nursing researchers, projects, and funding should be focused on this important area.

\section{Conflicts of Interest}

The authors declare no conflicts of interest regarding this review. 


\section{References}

[1] Lasalvia, A., Zoppei, S., Van Bortel, T., Bonetto, C., Cristofalo, D., Wahlbeck, K., Bacle, S.V., Van Audenhove, C., Van Weeghel, J., Reneses, B. and Germanavicius, A. (2013) Global Pattern of Experienced and Anticipated Discrimination Reported by People with Major Depressive Disorder: A Cross-Sectional Survey. The Lancet, 381, 55-62. https://doi.org/10.1016/S0140-6736(12)61379-8

[2] Thornicroft, G., Brohan, E., Rose, D., Sartorius, N., Leese, M. and INDIGO Study Group (2009) Global Pattern of Experienced and Anticipated Discrimination against People with Schizophrenia: A Cross-Sectional Survey. The Lancet, 373, 408-415. https://doi.org/10.1016/S0140-6736(08)61817-6

[3] Hamdan-Mansour, A.M. and Wardam, L.A. (2009) Attitudes of Jordanian Mental Health Nurses toward Mental Illness and Patients with Mental Illness. Issues in Mental Health Nursing, 30, 705-711. https://doi.org/10.1080/01612840903131792

[4] Corrigan, P.W. (2000) Mental Health Stigma as Social Attribution: Implications for Research Methods and Attitude Change. Clinical Psychology. Science and Practice, 7, 48-67. https://doi.org/10.1093/clipsy.7.1.48

[5] Larson, J.E. and Corrigan, P. (2008) The Stigma of Families with Mental Illness. Academic Psychiatry, 32, 87-91. https://doi.org/10.1176/appi.ap.32.2.87

[6] Corrigan, P.W. and Watson, A.C. (2002) Understanding the Impact of Stigma on People with Mental Illness. World Psychiatry, 1, 16-20.

[7] Levey, S. and Howells, K. (1994) Accounting for the Fear of Schizophrenia. Journal of Community and Applied Social Psychology, 4, 313-328. https://doi.org/10.1002/casp.2450040502

[8] Ogunsemi, O.O., Odusan, O. and Olatawura, M.O. (2008) Stigmatising Attitude of Medical Students towards a Psychiatry Label. Annals of General Psychiatry, 7, 15. https://doi.org/10.1186/1744-859X-7-15

[9] Socall, D.W. and Holtgraves, T. (1992) Attitudes toward the Mentally Ill: The Effects of Label and Beliefs. Sociological Quarterly, 33, 435-445. https://doi.org/10.1111/j.1533-8525.1992.tb00383.x

[10] Yamaguchi, S., Wu, S.I., Biswas, M., Yate, M., Aoki, Y., Barley, E.A. and Thornicroft, G. (2013) Effects of Short-Term Interventions to Reduce Mental Health-Related Stigma in University or College Students: A Systematic Review. The Journal of Nervous and Mental Disease, 201, 490-503. https://doi.org/10.1097/NMD.0b013e31829480df

[11] Sandhu, H.S., Arora, A., Brasch, J. and Streiner, D.L. (2018) Mental Health Stigma: Explicit and Implicit Attitudes of Canadian Undergraduate Students, Medical School Students, and Psychiatrists. The Canadian Journal of Psychiatry, 64, 209-217. https://doi.org/10.1177/0706743718792193

[12] El-Etreby, R.R., Ibrahim, A.A.W. and Shahda, M.M. (1940) Stigma in Nursing Students towards Patients with Mental Illness. IOSR Journal of Nursing and Health Science, 6, 94-100. https://doi.org/10.9790/1959-06020794100

[13] Hassona, Y.M., Mahmoud, A.A.A.A., Ryalat, S.M. and Sawair, F.A. (2014) Dental Students' Knowledge and Attitudes toward Patients with Epilepsy. Epilepsy and Behavior, 36, 2-5. https://doi.org/10.1016/j.yebeh.2014.04.008

[14] Ha, J.E. and Hong, S.M. (2016) Survey on Knowledge Level, Perception, and Attitudes of Dental Hygiene Students toward Mental Disorders in Korea. Indian Journal of Science and Technology, 9, 43. https://doi.org/10.17485/ijst/2016/v9i43/105016

[15] Bell, J.S., Aaltonen, S.E., Bronstein, E., Desplenter, F.A., Foulon, V., Vitola, A., Muceniece, R., Gharat, M.S., Volmer, D., Airaksinen, M.S. and Chen, T.F. (2008) Atti- 
tudes of Pharmacy Students toward People with Mental Disorders, a Six Country Study. Pharmacy World and Science, 30, 595-599.

https://doi.org/10.1007/s11096-008-9211-x

[16] Chung, K.F., Chen, E.Y. and Liu, C.S. (2001) University Students' Attitudes towards Mental Patients and Psychiatric Treatment. International Journal of Social Psychiatry, 47, 63-72. https://doi.org/10.1177/002076400104700206

[17] Covarrubias, I. and Han, M. (2011) Mental Health Stigma about Serious Mental Illness among MSW Students: Social Contact and Attitude. Social Work, 56, 317-325. https://doi.org/10.1093/sw/56.4.317

[18] Todor, I. (2013) Opinions about Mental Illness. Procedia-Social and Behavioral Sciences, 82, 209-214. https://doi.org/10.1016/j.sbspro.2013.06.247

[19] Poreddi, V., Thimmaiah, R. and BadaMath, S. (2017) Medical and Nursing Students' Attitudes toward Mental Illness: An Indian Perspective. Investigacion y Educacion en Enfermeria, 35, 86-94. https://doi.org/10.17533/udea.iee.v35n1a10

[20] Svensson, B., Brunt, D., Bejerholm, U., Eklund, M., Lundvik Gyllensten, A., Leufstadius, C., Markström, U., Sandlund, M., Östman, M. and Hansson, L. (2014) Health Care Students Attitudes towards People with Schizophrenia: A Survey of Eight University Training Programs. Open Journal of Psychiatry, 4, 309-316. https://doi.org/10.4236/ojpsych.2014.44038

[21] Ewalds-Kvist, B., Högberg, T. and Lützén, K. (2013) Impact of Gender and Age on Attitudes towards Mental Illness in Sweden. Nordic Journal of Psychiatry, 67, 360-368. https://doi.org/10.3109/08039488.2012.748827

[22] Linden, M. and Kavanagh, R. (2011) Attitudes of Qualified vs. Student Mental Health Nurses towards an Individual Diagnosed with Schizophrenia. Journal of Advanced Nursing, 68, 1359-1368. https://doi.org/10.1111/j.1365-2648.2011.05848.x

[23] Heim, E., Henderson, C., Kohrt, B.A., Koschorke, M., Milenova, M. and Thornicroft, G. (2019) Reducing Mental Health-Related Stigma among Medical and Nursing Students in Low- and Middle-Income Countries: A Systematic Review. Epidemiology and Psychiatric Sciences, 29, 1-9. https://doi.org/10.1017/S2045796019000167

[24] Corrigan, P. (2004) How Stigma Interferes with Mental Health Care. American Psychologist, 59, 614-625. https://doi.org/10.1037/0003-066X.59.7.614

[25] Thornicroft, G. (2008) Stigma and Discrimination Limit Access to Mental Health Care. Epidemiology and Psychiatric Sciences, 17, 14-19. https://doi.org/10.1017/S1121189X00002621

[26] Corrigan, P.W., Morris, S.B., Michaels, P.J., Rafacz, J.D. and Rüsch, N. (2012) Challenging the Public Stigma of Mental Illness: A Meta-Analysis of Outcome Studies. Psychiatric Services, 63, 963-973. https://doi.org/10.1176/appi.ps.201100529

[27] Couture, S. and Penn, D. (2003) Interpersonal Contact and the Stigma of Mental Illness: A Review of the Literature. Journal of Mental Health, 12, 291-305. https://doi.org/10.1080/09638231000118276

[28] Griffiths, K.M., Carron Arthur, B., Parsons, A. and Reid, R. (2014) Effectiveness of Programs for Reducing the Stigma Associated with Mental Disorders. A Meta-Analysis of Randomized Controlled Trials. World Psychiatry, 13, 161-175. https://doi.org/10.1002/wps.20129

[29] Gronholm, P.C., Henderson, C., Deb, T. and Thornicroft, G. (2017) Interventions to Reduce Discrimination and Stigma: The State of the Art. Social Psychiatry and Psychiatric Epidemiology, 52, 249-258. https://doi.org/10.1007/s00127-017-1341-9 
[30] Kolodziej, M.E. and Johnson, B.T. (1996) Interpersonal Contact and Acceptance of Persons with Disorders: A Research Synthesis. Journal of Consulting and Clinical Psychology, 64, 1387-1396. https://doi.org/10.1037/0022-006X.64.6.1387

[31] Mehta, N., Clement, S., Marcus, E., Stona, A.C., Bezborodovs, N., Evans-Lacko, S., Palacios, J., Docherty, M., Barley, E., Rose, D. and Koschorke, M. (2015) Evidence for Effective Interventions to Reduce Mental Health-Related Stigma and Discrimination in the Medium and Long Term: Systematic Review. The British Journal of Psychiatry, 207, 377-384. https://doi.org/10.1192/bjp.bp.114.151944

[32] Morgan, A.J., Reavley, N.J., Ross, A., San Too, L. and Jorm, A.F. (2018) Interventions to Reduce Stigma towards People with Severe Mental Illness: Systematic Review and Meta-Analysis. Journal of Psychiatric Research, 103, 120-133. https://doi.org/10.1016/j.jpsychires.2018.05.017

[33] Pinto-Foltz, M.D. and Logsdon, M.C. (2009) Reducing Stigma Related to Mental Disorders: Initiatives, Interventions, and Recommendations for Nursing. Archives of Psychiatric Nursing, 23, 32-40. https://doi.org/10.1016/j.apnu.2008.02.010

[34] Stubbs, A. (2014) Reducing Mental Illness Stigma in Health Care Students and Professionals: A Review of the Literature. Australasian Psychiatry, 22, 579-584. https://doi.org/10.1177/1039856214556324

[35] Thornicroft, G., Mehta, N., Clement, S., Evans-Lacko, S., Doherty, M., Rose, D., Koschorke, M., Shidhaye, R., O’Reilly, C. and Henderson, C. (2016) Evidence for Effective Interventions to Reduce Mental-Health-Related Stigma and Discrimination. The Lancet, 387, 1123-1132. https://doi.org/10.1016/S0140-6736(15)00298-6

[36] Yamaguchi, S., Mino, Y. and Uddin, S. (2011) Strategies and Future Attempts to Reduce Stigmatization and Increase Awareness of Mental Health Problems among Young People: A Narrative Review of Educational Interventions. Psychiatry and Clinical Neurosciences, 65, 405-415. https://doi.org/10.1111/j.1440-1819.2011.02239.x

[37] Abuhammad, S., Hatamleh, R., Howard, K. and Ahmad, M.M. (2018) Correlates and Predictors of Stigmatization of Patients with Mental Illness among Nursing Students. Journal of Psychosocial Nursing and Mental Health Services, 57, 43-51. https://doi.org/10.3928/02793695-20180907-01

[38] Hamaideh, S. and Mudallal, R. (2009) Attitudes of Jordanian Nursing Students towards Mental Illness: The Effect of Teaching and Contact on Attitudes Change. College Student Journal, 43, 335-346.

[39] Conn, V.S., Isaramalai, S.A., Rath, S., Jantarakupt, P., Wadhawan, R. and Dash, Y. (2003) Beyond MEDLINE for Literature Searches. Journal of Nursing Scholarship, 35, 177-182. https://doi.org/10.1111/j.1547-5069.2003.00177.x

[40] Conn, V.S., Valentine, J.C., Cooper, H.M. and Rantz, M.J. (2003) Grey Literature in Meta-Analyses. Nursing Research, 52, 256-261.

https://doi.org/10.1097/00006199-200307000-00008

[41] Imperio, S.M. (2016) A Filmed-Contact Intervention to Reduce Mental Illness Stigma in Pre-Licensure Nursing Students. DNP Thesis, Brandman University, Irvine.

[42] Winkler, P., Janoušková, M., Kožený, J., Pasz, J., Mladá, K., Weissová, A., Tušková, E. and Evans-Lacko, S. (2017) Short Video Interventions to Reduce Mental Health Stigma: A Multi-Centre Randomised Controlled Trial in Nursing High Schools. Social Psychiatry and Psychiatric Epidemiology, 52, 1549-1557.

https://doi.org/10.1007/s00127-017-1449-y

[43] Roberts, L.M., Wiskin, C. and Roalfe, A. (2008) Effects of Exposure to Mental Illness in Role-Play on Undergraduate Student Attitudes. Family Medicine, 40, 
477-483.

[44] Iheanacho, T., Marienfeld, C., Stefanovics, E. and Rosenheck, R.A. (2014) Attitudes toward Mental Illness and Changes Associated with a Brief Educational Intervention for Medical and Nursing Students in Nigeria. Academic Psychiatry, 38, 320-324. https://doi.org/10.1007/s40596-014-0073-3

[45] Webster, D. (2010) Promoting Empathy through a Creative Reflective Teaching Strategy: A Mixed-Method Study. Journal of Nursing Education, 49, 87-94. https://doi.org/10.3928/01484834-20090918-09

[46] Sarikoc, G., Ozcan, C.T. and Elcin, M. (2017) The Impact of Using Standardized Patients in Psychiatric Cases on the Levels of Motivation and Perceived Learning of the Nursing Students. Nurse Education Today, 51, 15-22. https://doi.org/10.1016/j.nedt.2017.01.001

[47] Brown, J.F. (2009) Faith-Based Mental Health Education: A Service-Learning Opportunity for Nursing Students. Journal of Psychiatric and Mental Health Nursing, 16, 581-588. https://doi.org/10.1111/j.1365-2850.2009.01421.x

[48] Clement, S., van Nieuwenhuizen, A., Kassam, A., Flach, C., Lazarus, A., De Castro, M., McCrone, P., Norman, I. and Thornicroft, G. (2012) Filmed v. Live Social Contact Interventions to Reduce Stigma: Randomised Controlled Trial. The British Journal of Psychiatry, 201, 57-64. https://doi.org/10.1192/bjp.bp.111.093120

[49] Coleman, T.E. (2007) The Effects of Age and Exposure to Mental Illness Educational Material on Student Nurses' Attitudes toward the Mentally Ill. Psy. D. Thesis, Hofstra University, New York.

[50] Happell, B., Byrne, L., Platania-Phung, C., Harris, S., Bradshaw, J. and Davies, J. (2014) Lived-Experience Participation in Nurse Education: Reducing Stigma and Enhancing Popularity. International Journal of Mental Health Nursing, 23, 427-434. https://doi.org/10.1111/inm.12077

[51] İnan, F.Ş., Günüşen, N., Duman, Z.Ç. and Ertem, M.Y. (2019) The Impact of Mental Health Nursing Module, Clinical Practice and an Anti-Stigma Program on Nursing Students' Attitudes toward Mental Illness: A Quasi-Experimental Study. Journal of Professional Nursing, 35, 201-208. https://doi.org/10.1016/j.profnurs.2018.10.001

[52] Itzhaki, M., Meridan, O., Sagiv-Schifter, T. and Barnoy, S. (2017) Nursing Students' Attitudes and Intention to Work with Mentally Ill Patients before and after a Planned Intervention. Academic Psychiatry, 41, 337-344.

https://doi.org/10.1007/s40596-016-0521-3

[53] Martínez-Martínez, C., Sánchez-Martínez, V., Sales-Orts, R., Dinca, A., Richart-Martínez, M. and Ramos-Pichardo, J.D. (2019) Effectiveness of Direct Contact Intervention with People with Mental Illness to Reduce Stigma in Nursing Students. International Journal of Mental Health Nursing, 28, 735-743.

https://doi.org/10.1111/inm.12578

[54] Sadow, D. and Ryder, M. (2008) Reducing Stigmatizing Attitudes Held by Future Health Professionals: The Person Is the Message. Psychological Services, 5, 362-372. https://doi.org/10.1037/1541-1559.5.4.362

[55] Vaghee, S., Lotfabadi, M.K., Salarhaji, A., Vaghei, N. and Hashemi, B.M. (2018) Comparing the Effects of Contact-Based Education and Acceptance and Commitment-Based Training on Empathy toward Mental Illnesses among Nursing Students. Iranian Journal of Psychiatry, 13, 119-127.

[56] Thornicroft, G., Rose, D., Kassam, A. and Sartorius, N. (2007) Stigma: Ignorance, Prejudice or Discrimination? The British Journal of Psychiatry, 190, 192-193. https://doi.org/10.1192/bjp.bp.106.025791 